\title{
intuitio
}

Revista do PPG em Filosofia da PUCRS

doi http://dx.doi.org/10.15448/1983-4012.2019.1.26666

\section{A CIDADE DE SÓCRATES: ENSAIO SOBRE A NATUREZA DA VERDADEIRA ARTE POLÍTICA EM GÓRGIAS}

\author{
THE CITY OF SOCRATES: ESSAY ON THE NATURE OF TRUE \\ POLITICAL ART IN GORGIAS
}

Raquel de Azevedo'

Resumo: Este trabalho se propõe a indagar em que consiste a recalcitrância de Cálicles, que Sócrates reconhece como sua pedra de toque, no diálogo Górgias de Platão. A chave de leitura para pensar o não-diálogo entre Cálicles e Sócrates está, segundo minha hipótese, na analogia entre os amantes dos dois personagens. Os amantes de Sócrates, Alcebíades e a filosofia, são a interiorização (e não a eliminação) do conflito externo com Cálicles. Segundo Hannah Arendt, o acordo consigo mesmo é a resposta socrática à irredutibilidade de Cálicles. Com essa operação, Platão cria uma complexa relação entre os dois modos de vida em jogo e, pela correspondência entre a alma e a cidade, o não-diálogo se desdobra em duas cidades distintas, uma sendo o avesso da outra, como na anedota acerca dos dois discursos sobre Helena proferidos pelo Górgias histórico - que dá nome ao diálogo.

Palavras-chave: Górgias. Platão. Cálicles. Recalcitrância.

\footnotetext{
- Doutoranda em Filosofia, Programa de Pós-Graduação em Filosofia - PUC-Rio. Bolsista CAPES. ORCID: http://orcid.org/oooo-0002-7373-3104. E-MAIL: raquelazevedo@gmail.com
} 


\begin{abstract}
This work aims to investigate in what consists Callicles' recalcitrance in Plato's Gorgias. The key to the non-dialogue between Callicles and Socrates is, according to my hypothesis, the analogy between the lovers of the two characters. Socrates' lovers, Alcebiades and philosophy, are an internalization (not an elimination) of the external conflict with Callicles. With this operation, Plato creates a complex relationship between the two modes of life at stake and, by the correspondence between soul and city, the non-dialogue unfolds itself in two distinct cities, one being the reverse of the other, as in the anecdote of the two speeches about Helena delivered by the historical Gorgias - who gives name to the dialogue.
\end{abstract}

Keywords: Gorgias. Plato. Callicles. Recalcitrance.

Cálicles, célebre interlocutor de Sócrates com quem a dialética não funciona, ocupa uma posição peculiar no esquema analógico de Platão em Górgias. Enquanto os demais pares de personagens do diálogo parecem indicar uma relação entre mestre e discípulo, entre uma determinada arte e aquilo que ela produz - vejam-se Górgias e Polo, Sócrates e Querefonte -, Cálicles, terceira figura a ser submetida ao elenchos socrático, tem como par o não-diálogo, aquilo que ele produz é precisamente o não funcionamento da dialética. Mas o que exatamente falha quando a dialética falha? Minha hipótese é que essa é a forma negativa de se perguntar em que consiste a arte de Sócrates. Cálicles, como o próprio Sócrates reconhece, é sua pedra de toque (486d2-e2), mas só pode dizer algo sobre a arte socrática às avessas, perturbando e inviabilizando completamente o processo de homologia. É, pois, ao proferir nomes sem nada indicar com eles (489e5-6), ou ainda, ao jamais dizer as mesmas coisas sobre os mesmos assuntos (491b7-8), que Cálicles estabelece um abismo instransponível entre seu hedonismo e o modo de vida socrático.

A analogia entre os dois amantes de Sócrates e Cálicles a um só tempo confirma e torna mais complexa a distinção entre os modos de vida em jogo. Enquanto as paixões caliclianas são o demo de Atenas e Demo, filho de Pirilampo, Sócrates ama Alcebíades, filho de Clínias, e a filosofia (481d2-4). O paralelismo que Daniel Lopes (2014a) identifica 
entre a filosofia e a política democrática de Atenas, isto é, entre o discurso unívoco do filósofo, que sempre diz as mesmas coisas sobre os mesmos assuntos, e o discurso volúvel do político, cujas opiniões variam com as circunstâncias e com o público a que se volta, sofre um inequívoco desequilíbrio com a presença de um elemento vulnerável no pólo socrático. Alcebíades não é estável como a filosofia, pelo contrário, é aos amantes de Cálicles que se assemelha. Significa dizer que Sócrates não é um personagem que elimina o conflito em seu íntimo, mas incorpora-o, ou, dito de outra forma, os dois amantes socráticos, Alcebíades e a filosofia, interiorizam a oposição maior entre os dois modos de vida confrontados

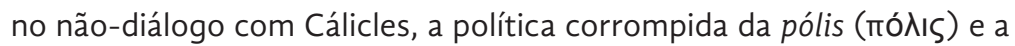
verdadeira política, respectivamente. Com essa operação, Platão parece fazer do personagem de Sócrates um mecanismo responsável por replicar o conflito e a busca pela ordenação nas mais diferentes esferas do discurso. Podemos dizer que Platão reproduz, através de Sócrates, o alinhamento que vai do cosmos ao logos, passando pelo corpo e pela alma, na célebre abertura do Elogio de Helena de Górgias.

Em A dignidade da política, Hannah Arendt identifica nesse procedimento platônico de interiorização do máximo desacordo de Sócrates com Cálicles uma antecipação do axioma da contradição de Aristóteles. Ou seja, as paixões socráticas indicam um movimento em direção à necessidade de se ser um consigo mesmo ainda que o dois-em-um do pensamento (que se constitui como uma unidade quando se contrapõe a algo fora dele) esteja contra o mundo. Essa é a conclusão a que chega Sócrates em seu pequeno discurso sobre os amantes:

[É] melhor que minha lira, ou coro do qual sou corego, seja desafinada e dissonante e que a maioria dos homens não concorde comigo e afirme o contrário do que digo, do que 
eu, sendo um só, dissone de mim mesmo e diga coisas contraditórias $(482 \mathrm{~b} 8-\mathrm{c} 2)^{2}$.

Antes de nos perguntar o que produz essa não-contradição socrática, vejamos em que consiste o mundo duplamente adulador de Cálicles. Ao testar o paralelismo entre a alma e a cidade no Livro II da República, esta sendo um experimento ampliado daquela, Sócrates imagina um lugar que se constitui pelo acréscimo de homens dedicados cada qual a uma atividade específica (o agricultor, o pedreiro, o tecelão), até que, nas palavras de Glauco, deixe de ser uma cidade de porcos e incorpore uma multidão de indivíduos que lá não se encontram por necessidade, como os poetas e os guardiões. As várias camadas da cidade platônica são várias camadas de pleonexia, do querer mais, e há um certo caráter irreversível nesse processo

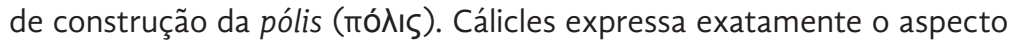
dissipativo da pleonexia, isto é, a perda irrecuperável associada ao querer mais no âmbito da cidade ou da alma. Na passagem da cidade dos porcos à cidade que inclui guardiões e poetas, o índice dessa perda é o aumento populacional. Para Platão, essa população excedente está vinculada ao problema da guerra e, consequentemente, da educação para a guerra.

Quanto à irreversibilidade da pleonexia na alma, é Trasímaco que a define, no Livro I da República, ao conceber que a injustiça, quando levada a um grau suficiente, é mais livre e forte (344c3). O homem que se deixa apanhar cometendo pequenos delitos é punido e recebe os piores castigos, mas quando pratica a mais perfeita injustiça, chamam-no feliz e afortunado. Há um limiar, responsável pela própria origem da noção de justiça enquanto posição intermediária entre a impunidade e a impotência para se vingar, que quando ultrapassado em uma democracia decadente, pode produzir a figura do tirano. Tudo se passa como se a política dos tribunais e das assembleias possuísse um caráter entrópico, uma tendência inelutável à desordem, sendo a justiça uma contratendência, um meca-

2 PLATÃO. Górgias. Daniel R. N. Lopes. São Paulo: Perspectiva, 2014a, p. 295. 
nismo de produção de ordem. A democracia ateniense seria um estado metaestável do sistema político na medida em que certas perturbações podem fazê-la transitar para o estado mais estável a que tende o sistema, que, segundo a tese de Trasímaco, é a injustiça.

Compreendê-lo-ás, porém, mais facilmente se fores até a mais perfeita injustiça, a que leva ao cúmulo de felicidade o homem que a comete, e no cúmulo da desgraça os que a sofrem e não querem cometê-la. Esta injustiça é a tirania que, por meio de fraude e violência, se apodera do bem alheio: sagrado, profano, particular, público, e não por partes, mas tudo de uma vez. Diante de cada um desses delitos, o homem que se deixa apanhar é punido e coberto dos piores estigmas; com efeito, costuma-se tratar estas criaturas que operam por miúdo, de sacrílegas, traficantes de escravos, arrombadores de paredes, espoliadores, ladrões, conforme a injustiça cometida. Mas quando um homem, além da fortuna dos cidadãos, se apodera de suas pessoas e os subjuga, em vez de receber nomes vergonhosos, chamam-no feliz e afortunado, não só os cidadãos, mas ainda todos os que venham a saber que ele praticou injustiça em toda a extensão; pois os que a censuram não temem cometer injustiça: temem sofrê-la. Assim, Sócrates, a injustiça, levada a um grau suficiente, é mais forte, mais livre, mais digna de um senhor do que a justiça, e, como eu afirmava no começo, a justiça consiste na vantagem do mais forte e a injustiça só age em vantagem e proveito próprios (344a3-c6)3.

A forma como Sócrates refuta Trasímaco passa, antes de tudo, pela indicação do modo como se elabora um lugar, o topos da verdadeira política. Em vez de descrever uma cidade específica, como nas tintas modernas de Thomas More na Utopia, o método socrático sinaliza que esse lugar se dá

3 PLATÃO. A República de Platão. J. Guinsburg. 2. ed. São Paulo: Perspectiva, 2014b, p. 46. 
sempre que se é um com sua própria alma. Quando a dialética logra obter uma homologia entre os interlocutores, abre-se um "espaço de comunidade", nas palavras de Christopher Long, uma espécie de cidade que não se dá a ver do alto, de uma perspectiva fora dela, mas sempre parcialmente, nos próprios diálogos, através dos interlocutores específicos.

O topos socrático consiste em um paralelismo muito específico entre vida pública e vida privada. Sócrates ocuparia uma posição intermediária entre a máxima identidade entre público e privado pensada ora a partir da supressão do público a partir da onipotência do privado, que teria sua expressão na alegoria do anel de Giges, ora pela supressão do privado pela supremacia do público, que, ao eliminar toda a possibilidade de estar só, traria a própria marca das organizações totalitárias de massa, como argumenta Hannah Arendt. O anel que confere invisibilidade àquele que o usa com o engaste voltado para dentro evidenciaria que a justiça não é um bem em si, mas é apenas tolerada por homens impotentes para cometer injustiça. Glauco conclui, com Trasímaco, que a justiça seria uma força contrária à tendência entrópica da injustiça. A experiência com a invisibilidade seria o atestado de que a injustiça é o estado de equilíbrio do sistema político.

Se, pois, existissem dois anéis desta espécie e se o justo recebesse um, e o injusto outro, nenhum dos dois seria, ao que se pensa, de natureza tão diamantina a ponto de perseverar na justiça e ter a coragem de não tocar no bem de outrem, já que poderia tomar sem receio, na ágora, tudo o que quisesse, introduzir-se nas casas para unir-se a quem Ihe agradasse, matar ou libertar da prisão quem bem entendesse e fazer tudo a seu bel-prazer, convertido como que num deus entre os homens. Procedendo assim, nada o distinguiria do mau: ambos tenderiam para o mesmo fim. $E$ citar-se-ia isso como a grande prova de que ninguém é justo voluntariamente, mas por coerção, não constituindo a justiça 
um bem em si, pois quem se crê capaz de cometer a injustiça a comete $(360 \mathrm{~b} 1-\mathrm{c} 7)^{4}$.

No polo oposto à alegoria do anel de Giges está a identidade entre público e privado a partir da aniquilação da possibilidade de estar só. Hannah Arendt explica que a descoberta socrática acerca da solidão, que aos olhos da democracia ateniense era antipolítica, consiste na descoberta de uma

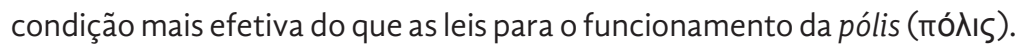
A disposição dos elementos da alma guarda uma relação proporcional

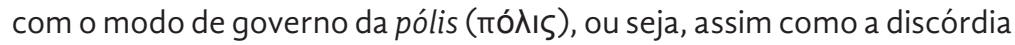
em seu íntimo torna um homem incapaz de agir, as dissensões entre os cidadãos fariam com que brigassem entre si e se tornassem impotentes de empreender qualquer coisa em comum. A porção dessa analogia que preocupa Hannah Arendt particularmente é, no entanto, a aniquilação dos fragmentos da alma e, portanto, do diálogo consigo mesmo. Não é difícil reconhecer aí a marca dos regimes totalitários.

Nós [...] que tivemos a nossa experiência com as organizações totalitárias de massa, cuja primeira preocupação é eliminar toda possibilidade de estar-só - exceto na forma desumana do confinamento solitário -, podemos facilmente atestar que se deixa de existir a garantia de uma mínima possibilidade de se estar só consigo mesmo, não só as formas seculares, como todas as formas religiosas de consciência serão abolidas. $\mathrm{O}$ fato frequentemente observado de que a própria consciência deixa de funcionar sob condições totalitárias de organização política - e isso sem levar em conta o medo e o castigo - é explicável por esse motivo. Ninguém que não possa realizar o diálogo consigo mesmo, isto é, que careça do estar-só

4 PLATÃo. A República de Platão. J. Guinsburg. 2. ed. São Paulo: Perspectiva, 2014b, p. 65. 
necessário para todas as formas de pensar, pode manter sua consciência moral intacta 5 .

Platão se vale da condição de dois-em-um do pensamento para refutar, através do discurso socrático sempre orientado pela não-contradição, as possibilidades atraentes associadas ao anel de Giges, pois mesmo que não seja visto por ninguém, um homem não matará outrem por não desejar estar junto de um assassino ${ }^{6}$. O que Platão encontra no personagem de Sócrates, que é sempre um consigo mesmo, é a possibilidade de elaborar uma noção de verdade a partir da consistência do discurso. Essa verdade o permite recusar uma interpretação trágica do julgamento de Sócrates, no qual o filósofo submeteu sua doxa às opiniões dos juízes e se mostrou incapaz de persuadi-los. O objetivo da dialética não seria, assim, extrair a verdade pela destruição da doxa; trata-se, nas palavras de Hannah Arendt, de revelar a doxa em sua própria verdade. Se a doxa é a formulação em fala daquilo que lhe parece, isto é, do modo como o mundo se abre para um sujeito, o critério para que o homem diga sua doxa com verdade é que ele esteja de acordo consigo mesmo. Esse é o produto da dialética: a produção da homologia sem a eliminação do conflito. Já a recalcitrância de Cálicles ao elenchos socrático expressa em negativo a possibilidade de comunidade com o outro, o que leva Sócrates a ter de conduzir a parte final do diálogo sendo dois-em-um. Os espectadores da conversa são convocados a participar passivamente na medida em que devem indicar se Sócrates concorda consigo mesmo a respeito de coisas que não são o caso.

\footnotetext{
5 ARENDT, H. A dignidade da política. 3. ed. Rio de Janeiro: Relume Dumará, 2002, p. 104-105.

6 "Ou, falando de modo mais socrático - pois embora Sócrates tenha descoberto a consciência, ele ainda não tinha um nome para ela -, a razão pela qual não devemos matar, mesmo quando não podemos ser vistos por ninguém, é que não queremos de modo algum estar junto a um assassino. Ao cometer um assassinato, estaríamos nos entregando à companhia de um assassino enquanto vivêssemos". (ARENDT, H. A dignidade da política. 3. ed. Rio de Janeiro: Relume Dumará, 2002, p. 102-103)
} 
Para me valer do dito de Epicarmo, eu serei suficiente, mesmo sendo um só, para o que "dois homens diziam previamente". Pois bem, é provável que isso seja absolutamente necessário. Todavia, se tomarmos essa decisão, julgo que todos nós devamos almejar a vitória em saber o que é verdadeiro e o que é falso em relação ao que dizemos, pois é um bem comum a todos que isso se esclareça. Farei a exposição do argumento, então, como me parecer melhor [grifo nosso], mas se algum de vós achar que eu concordo comigo mesmo a respeito de coisas que não são o caso, será seu dever, então, tomar a palavra e refutar-me. Pois eu, de fato, não falo como conhecedor do que falo, mas empreendo convosco uma investigação em comum, de modo que, se quem diverge de mim disser-me algo manifesto, serei o primeiro a consenti-lo (505e-506a6)7.

O diálogo com Cálicles caminha para um desfecho com Sócrates expondo sua doxa ao exame através da makrologia, o método de discursos longos que ele havia proibido Górgias de utilizar em favor da brakhulogia, os discursos breves. Hannah Arendt ressalta, no entanto, que mesmo a forma aparente do monólogo contém a condição de pluralidade. A operação lógica através da qual Platão faz o personagem de Sócrates internalizar a oposição entre a verdadeira política e a política corrom-

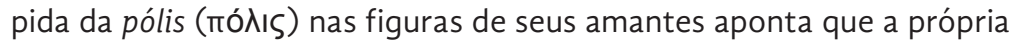
natureza da dialética é a possibilidade de replicação da guerra civil e de seus termos de paz tanto na cidade quanto na alma. A recalcitrância de Cálicles não significa a abolição da dialética, mas sua redução à dinâmica da não-contradição consigo mesmo.

O axioma da contradição, com o qual Aristóteles fundou a lógica ocidental, poderia remontar a essa descoberta fundamental de Sócrates [a não-contradição consigo mesmo].

PLATÃO. Górgias. Daniel R. N. Lopes. São Paulo: Perspectiva, 2014a, p. 379-381. 
Já que eu sou um, não irei contradizer-me, mas posso contradizer-me porque em pensamento sou dois-em-um; logo, não vivo apenas com os outros, enquanto um, mas também comigo mesmo. O medo da contradição é o medo de fragmentar-se, de não continuar sendo um, e é esta a razão pela qual o axioma da contradição pôde tornar-se a regra fundamental do pensamento. Esta é também a razão pela qual a pluralidade dos homens não pode ser inteiramente abolida; e é por isso que a saída do filósofo da esfera da pluralidade é sempre uma ilusão: ainda que eu tivesse que viver inteiramente sozinho, estando vivo, eu viveria na condição de pluralidade. Tenho que me suportar, e não há lugar em que o eu-comigo-mesmo se mostre mais claramente do que no pensamento puro, sempre um diálogo entre os dois que sou. O filósofo que, tentando escapar da condição humana de pluralidade, foge para a solidão total, entrega-se, de forma mais radical do que qualquer outro, a essa pluralidade inerente a todo ser humano, pois é a companhia dos outros que, atraindo-me para fora do diálogo do pensamento torna-me novamente um - um ser só humano, único, falando apenas com uma voz e sendo reconhecido como tal por todos os outros ${ }^{8}$.

Ao disputar as regras do diálogo com Górgias, Sócrates parece indicar que a diferença na extensão do discurso é também uma diferença de natureza do discurso. Os discursos longos são o arranjo próprio ao discurso retórico, enquanto os discursos breves teriam a configuração própria ao diálogo socrático. Vemos, porém, que o tamanho do discurso também pode estar relacionado à dimensão da não-contradição. A makrologia com que Sócrates se engaja ao fim do diálogo tem a ordenação de alguém que é um consigo mesmo, ou seja, o monólogo traz as marcas de um conflito e de um acordo íntimos. A não-contradição com o mundo, por sua vez,

\footnotetext{
8 ARENDT, H. A dignidade da política. 3. ed. Rio de Janeiro: Relume Dumará, 2002, p. 101.
} 
é testada através da brakhulogia, através, portanto, da possibilidade de homologia entre os interlocutores. Cálicles indica a inoperância do método dos discursos breves, mas não elimina a possibilidade de reprodução da dialética em discursos longos.

A não-contradição consigo mesmo do personagem de Sócrates em seu monólogo parece redundar, por fim, na imaginação de uma cidade que será sempre análoga ao bom arranjo dos vários fragmentos da alma. A cidade socrática se opõe à cidade das assembleias, dos conselhos e dos tribunais de Górgias, Polo e Cálicles como se a apresentasse de cabeça para baixo (481c4), revirada por um discurso que testa o critério de verdade platônico. O empréstimo que Platão faz do Górgias do Elogio de Helena é pensar a verdade de um discurso a partir de um personagem que leva às últimas consequências as relações geométricas de proporção, desde o

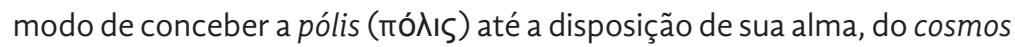
ao logos. O diálogo Górgias, por sua vez, é um problema de geometria no qual Cálicles é o elemento em que a relação de proporção não se completa. Sócrates internaliza e multiplica esse problema matemático em seu discurso e o resultado é a imaginação de uma cidade ao avesso.

Sócrates conhece a cidade em que vive e isso o leva a fazer duas afirmações aparentemente contraditórias a respeito da política. Num primeiro momento diz a Polo que não é um político (473e7) e já no fim do diálogo com Cálicles garante ser o único a empreender a verdadeira arte política e a praticá-la (521d6-7). O que Sócrates nega ao recusar a política é o conjunto de testemunhas a que Polo recorre para ratificar sua opinião de que o tirano é o mais feliz dos homens. Sócrates não precisa senão de uma testemunha, "aquela com a qual eu discuto"9 (474a5), para testar a homologia dos discursos. Mais do que reafirmar seu método de analogias entre o corpo e a alma, a medicina e a justiça, a culinária e a retórica, Sócrates expressa em negativo, diante de Polo, a sua arte: a imaginação da 
cidade em conformidade com a alma. Quando, no confronto com Cálicles, afirma que é o único a empreender a verdadeira arte política, Sócrates finalmente descreve a cidade a que sua alma corresponde através de um tribunal onde um médico é julgado em meio a crianças sob a acusação de um cozinheiro. A atopia dessa formulação de Sócrates é do tamanho de seu abismo com o discurso de Cálicles.

Julgo que eu, e mais alguns poucos atenienses - para não dizer apenas eu -, sou o único contemporâneo a empreender a verdadeira arte política e a praticá-la. Assim, visto que não profiro os discursos que profiro em toda ocasião visando o deleite, mas o supremo bem e não o que é mais aprazível, e visto que não desejo fazer "essas sutilezas" aconselhadas por ti, eu decerto não saberei o que dizer no tribunal. Mas o argumento que me ocorre é o mesmo que expus a Polo, pois serei julgado como se fosse um médico a ser julgado em meio a crianças sob a acusação de um cozinheiro. Examina, então! Que defesa poderia fazer um homem como esse surpreendido por tal circunstância, se alguém o acusasse dizendo: "Crianças, esse homem aqui presente cometeu inúmeros males contra vós próprios, e corrompe vossos entes mais jovens lacerando-os e cauterizando-os, e vos deixa embaraçados emagrecendo-vos e sufocando-vos; ele vos oferta as mais acerbas porções e vos constrange à fome e à sede, diferente de mim, que vos empanturrava de toda sorte de coisa aprazível". O que achas que o médico, surpreendido por esse mal, poderia falar? Se ele dissesse a verdade, que "Eu fazia tudo isso, crianças, saudavelmente", que tamanho alarido, segundo a tua opinião, fariam juízes como esses? Não seria enorme? ${ }^{10}(521 \mathrm{~d} 5-522 \mathrm{a} 6)$

10 PLATÃo. Górgias. Daniel R. N. Lopes. São Paulo: Perspectiva, 2014a, p. 435-437. 
É possível avaliar a diferença entre os discursos de Sócrates e Cálicles através do duplo movimento de interiorização e exteriorização da recalcitrância calicliana ao elenchos socrático. A oposição flui de um não-diálogo externo para um conflito interno à alma e da alma novamente à forma do discurso longo. Pela correspondência entre a alma e a cidade, podemos assumir que o não-diálogo também se desdobra em duas cidades distintas, uma sendo o avesso da outra, como na anedota acerca dos dois discursos sobre Helena proferidos por Górgias"1 . A diplomacia entre essas cidades não é, porém, "como um brinquedo", tal qual a conclusão do Elogio, não há indiferença entre os dois modos de vida. Sua relação é de uma guerra em que uma das cidades, a de Sócrates, tem de lutar no interior da topologia da outra, a saber, nos discursos.

\section{REFERÊNCIAS}

ARENDT, H. A dignidade da política. 3. ed. Rio de Janeiro: Relume Dumará, 2002. GÓRGIAS. Elogio de Helena. Tradução de Daniela Paulinelli. Belo Horizonte: Anágnosis, 2009. Disponível em: http://anagnosisufmg.blogspot. com/2009/10/elogio-de-helena-gorgias.html. Acesso em: 25 nov. 2016. https://doi.org/10.22456/2236-3254.74405

LONG, C. P. Socratic and platonic political philosophy: practicing a politics of reading. [S.I.]: Cambridge University Press, 2014. https://doi. org/10.1017/9781139628891

PLATÃO. Górgias. São Paulo: Perspectiva, 2014a.

PLATÃO. A República de Platão. 2. ed. São Paulo: Perspectiva, 2014b.

1 Conta-se que um dia antes de proferir o discurso que visava absolver Helena de qualquer culpa ao enumerar as possíveis causas de sua fuga com Páris, Górgias teria deleitado o mesmo público com um discurso de acusação da mesma personagem. 